\title{
Patients' Perception of Care Provided to Patients with Prostate Cancer in Selected Tertiary Health Institutions in South-East Nigeria
}

\author{
M. Ibekwe ${ }^{1}$, E. C. Ndie $^{2}$, I. C. Ilo ${ }^{1}$, P. O. Ezenduka ${ }^{1}$ and K. S. Musa ${ }^{1}$ \\ 1. Department of Nursing Science, Nnamdi Azikiwe University, Nnewi Campus, Nnewi 435101, Nigeria \\ 2. Department of Nursing Science, Faculty of Health Science, National Open University of Nigeria, Plot 91 Cadastral Zone, Nnamdi
}

Azikiwe Expressway, Jabi-Abuja, Nigeria

\begin{abstract}
Prostate cancer was perceived to be low in Africa, but recent studies have highlighted increase in incidence and mortality rate in the region including Nigeria. Appropriate nursing management of patients with prostate cancer could help to reduce the mortality rate. A descriptive survey was used to ascertain the patients' perception of pre-operative and post-operative nursing care provided to patients with prostate cancer in Nnamdi Azikiwe University Teaching Hospital Nnewi, Anambra State, University of Nigeria Teaching Hospital Enugu, Enugu State and Federal Teaching Hospital Abakiliki, Ebonyi State in South East Nigeria. Structured questionnaire was used to elicit information from a sample of 274 respondents statistically drawn using stratified random sampling technique from a population of 876 . Result showed that patients perceived the post-operative care as satisfactory (80.1\%) and pre-operative nursing care as unsatisfactory (40\%). The hypothesis revealed that there is no significant difference $(p>0.05)$ in nursing care provided by the nurses in three selected health institutions. Based on the findings, the researchers recommended that there is need to empower nurses with more information on prostate cancer management especially in pre-operative care to enable them to provide suitable quality care.
\end{abstract}

Key words: Perception, prostate cancer, incidence rate, nursing management.

\section{Background of the Study}

Prostate cancer, which is a malignant tumor characterized by abnormal growth of the prostate gland, is a common cancer affecting the lives of millions of men worldwide [1]. Prostate gland is a male reproductive accessory organ that weighs about 25 grammes and located deep in the pelvis below the bladder. Large scale studies are in progress to determine how prostate cancer can be managed and prevented. Recorded evidence also showed that regular prostate cancer screening has reduced mortality rate [2]. Osegbe [3] conducted a study at University Teaching Hospital Ibadan in Nigeria and

Corresponding author: ELKENAH C. NDIE, Ph.D., associate professor, research fields: public and community health nursing. reported an increased incidence rate of prostate cancer in Nigeria as 127 per 100,000 with deaths rate of 20,000 annually. Also Bowa [4] in his study on incidence and mortality rate of the prostate cancer in Nigeria reported that majority of the prostate cancer patients (64\%) die within two years of hospital diagnosis in most tertiary health institutions due to patient's late presentation, poor management protocols and inadequate facilities.

Iman, Okunlade and Oladeji [5] in their study at University of Ilorin Teaching Hospital on perception of nursing care rendered to prostate cancer patients before their surgery reported that $68 \%$ of patients perceived the care as unsatisfactory while only $32 \%$ were satisfied. They recommended the need for improved patient's condition while hospitalized. Omar and Onokunde [6] at Jos University Teaching Hospital 
Plateau State reported similar cases of non-provision of care by the nurses which resulted to fragmentation of care and patients' unsatisfactory perception of care. Charlotte, Christian and Birgitte [7] in their study in the United Kingdom on perception of men with prostate cancer and their accessibility to information and nursing care from the care givers documented that men with prostate cancer treated with prostatectomy did not receive individualized support, care, information and dialogue they needed from the healthcare professionals including nurses, which led to feelings of uncertainty, insecurity and loss of control in treatments.

Although there are recorded advancements by the Government in terms of facilities for care provisions and training of personnel in prostate care management there are still gaps in care provision. The researchers have also observed that some nurses in some tertiary health institutions do not have skills to manage prostate cancer cases. This situation had resulted to fragmentation of care and high morbidity rate in men living with prostate cancer. Therefore, in order to improve more on nursing care of patients with prostate cancer and reduce morbidity and mortality rate, there is need to elicit perception of patients with prostate cancer on the nursing care provided to them at the selected tertiary health institutions.

The purpose of this study was to investigate the patients' perception of nursing care provided to patients with prostate cancer at selected tertiary health institutions in South East-Nigeria. The result of this study will hopefully provide the nurses with information on patients' perception of the care provided to them at the selected tertiary institutions. This will aid them in appropriate decisions with regards to implications of care to patients. Hopefully, it will also provide the management of the selected tertiary institutions with baseline nursing care activities required in the management of prostate cancer patients so that they will be motivated to provide the required facilities and management protocols.

\section{Materials and Methods}

The descriptive survey research design was used to conduct the research, since the present study seeks to ascertain the prostate cancer patients' perception of nursing care in three selected teaching hospitals in South East of Nigeria. The study population consists of 876 prostate cancer patients receiving treatment at the institutions. The sample size was determined from the known population using the Yaro Yamane's formula. Proportionate stratified sampling method was used to draw a sample size of 275. The sample distribution for the three institutions was NAUTH Nnewi $=66$, UNTH Enugu $=147$ and FETH Abakaliki $=62$. Structured questionnaire which was validated by experts was used for data collection. The reliability co-efficient result of the test items was 0.87 . Ethical approval was obtained from ethical committee of the three teaching hospitals. The patients were informed about the purpose of the study and that the data obtained from the study would be confidential and would not be shared with anybody to ensure privacy. They were given "Informed Consent Forms," and their consents were obtained. A total of 274 copies of questionnaire were correctly filled and collected and 99\% was the return rate. Data were coded and analyzed using SPSS 20. The research questions were answered and presented using frequency and percentages, while the hypothesis was analyzed using the chi-square test.

\section{Results}

Data in Table 1 above show the result of Patients' Perceptions of Pre-operative Care provided by the Nurses to Patients' with Prostate Cancer at the three tertiary health institutions. Findings show that 46 (16.7\%) were satisfied with nurses explanation of prostate cancer diagnosis to them and their relations to reduce their anxiety about the disease and 228 (83.7\%) were not satisfied. Only 39 (14.23\%) indicated being 
Table 1 Patients' perception of pre-operative care provided to patients' with prostate cancer at the selected tertiary health institutions.

\begin{tabular}{|c|c|c|c|c|}
\hline \multirow{3}{*}{ Pre-operative Nursing Care provided to prostate cancer patients } & \multicolumn{4}{|c|}{ Perceptions } \\
\hline & \multicolumn{2}{|c|}{ Satisfied } & \multicolumn{2}{|c|}{ Not satisfied } \\
\hline & $\mathrm{f}$ & $\%$ & $\mathrm{f}$ & $\%$ \\
\hline $\begin{array}{l}\text { Nurses explain prostate cancer diagnosis to the patients and his relations to } \\
\text { reduce anxiety }\end{array}$ & 46 & 16.7 & 228 & 83.7 \\
\hline Nurses clarify patient's questions about the disease. & 39 & 14.23 & 35 & 85.77 \\
\hline Nurses provide comfort and emotional support to patients. & 65 & 23.72 & 209 & 76.28 \\
\hline Nurses monitor vital signs and record findings. & 231 & 84.31 & 43 & 15.69 \\
\hline Nurses witness patient to sign consent form for surgery where necessary. & 188 & 68.61 & 86 & 31.89 \\
\hline Nurses administer drugs to patients when due and recorded it. & 213 & 77.74 & 61 & 22.26 \\
\hline Nurses provide privacy to patients. & 33 & 12.04 & 241 & 87.96 \\
\hline Nurses assist patient to have personal hygiene. & 165 & 60.22 & 109 & 39.78 \\
\hline Nurses care for the urinary catheter to prevent blockage. & 141 & 51.46 & 133 & 48.54 \\
\hline
\end{tabular}

No. of patients assessed $n=274$.

satisfied with how the nurses clarified their questions about the disease, 235 (85.77\%) were not satisfied, 65 (23.72\%) indicated being satisfied with how nurses provided them with comfort and emotional support and also encouraged their relations to support them which helped them to adjust to the disease conditions, 209 (76.28\%) indicated not satisfied.

The result also shows that 231 (84.31\%) were satisfied with nurses' performance of monitoring and recording of vital signs while 43 (15.69\%) were not satisfied, 59 (21.53\%) were satisfied with how the nurses explained treatment options of surgery and palliative care to them and their relations, 215 (78.47\%) were not satisfied, 188 (68.61\%) patients expressed being satisfied on how nurses assisted them to sign consent form for the surgery, 86 (31.89\%) expressed not satisfaction.

Totally, 213 (77.74\%) of patients were satisfied on how nurses administered their drugs at the appropriate time, 61 (22.26\%) were not satisfied, 33 (12.04\%) were satisfied with nurses performance in providing privacy to them, 241 (87.96\%) were not satisfied, 165 (60.22\%) indicated satisfaction on how nurses assisted them to attend to their personal hygiene, 109 (39.78\%) were not satisfied, 141 (51.46\%) indicated satisfaction on how nurses cared for their urinary catheter that prevented them from having urethral blockage as a result of blood clots, 133 (48.54\%) were not satisfied.
Data in Table 2 show the result of the Perception of Post-operative Care provided by the Nurses to Patients' with Prostate Cancer at the three tertiary health institutions. Findings show that 198 (72.26\%) patients indicated being satisfied on how nurses received them back to the ward after surgery, monitored their vital signs and recorded findings, 76 (27.74\%) were not satisfied, 131 (47.81\%) were satisfied on how nurses monitored their indwelling urinary catheter that prevented them from having urethral blockage due to blood clots, 143 (52.19\%) were not satisfied, 220 (80.29\%) patients were satisfied on how nurses relieved their pains with prescribed analgesics as at and when due, 54 (19.71\%) were not satisfied, 270 (98.54\%) were satisfied on how nurses monitored their operation site for bleeding, while 4 (1.46\%) were not satisfied, 102 (37.23\%) of patients indicated being satisfied with how nurses maintained their personal hygiene by helping them in bathing and oral hygiene, 172 (62.77\%) were not satisfied, 91 (33.21\%) of patients expressed satisfaction with nurses performance in giving them adequate care when their condition stabilized, 183 (66.79\%) were not satisfied, 113 (41.24\%) patients indicated satisfaction with how nurses were friendly to them and their relations/visitors, 161 (58.76\%) were not satisfied, 193 (70.44\%) patients showed satisfaction with how the nurses provided them with comfort and emotional supports, 81 (29.56\%) 
Table 2 Patients' perceptions of post-operative care provided to patients' with prostate cancer at the selected tertiary health institutions.

\begin{tabular}{|c|c|c|c|c|}
\hline \multirow{3}{*}{ Pre-operative nursing care provided to prostate cancer patients } & \multicolumn{4}{|c|}{ Perceptions } \\
\hline & \multicolumn{2}{|c|}{ Satisfied } & \multicolumn{2}{|c|}{ Not satisfied } \\
\hline & $\bar{f}$ & $\%$ & $\mathrm{f}$ & $\%$ \\
\hline $\begin{array}{l}\text { Nurses received patients back to the ward after the surgery and monitor vital } \\
\text { signs and record findings. }\end{array}$ & 198 & 72.26 & 76 & 27.74 \\
\hline Nurses monitor indwelling urinary catheter to prevent catheter blockage. & 131 & 47.81 & 143 & 52.19 \\
\hline Nurses relieve pain with prescribed analgesics as at and when due. & 220 & 80.29 & 54 & 19.71 \\
\hline Nurses monitor the operation site for bleeding. & 270 & 98.54 & 4 & 1.46 \\
\hline Nurses maintain personal hygiene of patient's e.g. bathing, oral hygiene. & 102 & 37.23 & 172 & 62.77 \\
\hline Nurses advised on diet when condition stabilizes. & 91 & 33.21 & 183 & 66.79 \\
\hline Nurses were friendly to patients and visitors/relations. & 113 & 41.24 & 161 & 58.76 \\
\hline Nurses provide comfort and emotional support to patients. & 93 & 70.44 & 81 & 29.56 \\
\hline Nurses dress operation site wound as at and when due. & 244 & 89.05 & 30 & 10.95 \\
\hline Nurses administer prescribed post-operative, antibiotics as at and when due. & 176 & 64.23 & 98 & 35.77 \\
\hline Nurses encourage early ambulation for patients post-operatively. & 153 & 55.8 & 121 & 44.16 \\
\hline $\begin{array}{l}\text { Nurses counsel patients on incontinence following catheter removal and } \\
\text { bladder training. }\end{array}$ & 185 & 67.52 & 89 & 32.48 \\
\hline $\begin{array}{l}\text { Nurses teach patients and family the need to visit the hospital for check up } \\
\text { after discharge. }\end{array}$ & 207 & 75.55 & 67 & 24.45 \\
\hline
\end{tabular}

No. of Patients assessed $n=274$.

Table 3 Analysis of hypothesis using the selected tertiary health institutions and the preoperative nursing care.

\begin{tabular}{|c|c|c|c|c|}
\hline \multirow{2}{*}{$\begin{array}{l}\text { Nurses explain prostate cancer diagnosis to the patient and } \\
\text { his relations to reduce anxiety. }\end{array}$} & \multicolumn{3}{|c|}{$\begin{array}{l}\text { Selected tertiary health institutions in } \\
\text { South Eastern Nigeria }\end{array}$} & \multirow{2}{*}{-Total } \\
\hline & NAUTH & UNTH & FETH & \\
\hline Satisfied & 6 & 14 & 5 & 25 \\
\hline Fairly Satisfied & 5 & 11 & 5 & 21 \\
\hline Not Satisfied & 49 & 107 & 47 & 203 \\
\hline I don't know & 6 & 14 & 5 & 25 \\
\hline Total & 66 & 146 & 62 & 274 \\
\hline
\end{tabular}

Chi-square result

\begin{tabular}{llll}
\hline Chi-square parameter & $X^{2}$-value & Df & $p$-value \\
\hline Values & 0.276 & 6 & 1.000 \\
\hline
\end{tabular}

$n=274$.

were not satisfied, 244 (89.05\%) were satisfied with how nurses dressed their operation wound as at and when due, 30 (10.95\%) were not satisfied, 176 (64.23\%) were satisfied with nurses' performance in administration of prescribed post-operative antibiotics as at and when due, 98 (37.77\%) were not satisfied, 153 (55.8\%) were satisfied with how nurses encouraged them to practice early ambulation post-operatively, 121 (44.16\%) were not satisfied, 185 (67.52\%) patients were satisfied with how nurses counseled them on incontinence following catheter removal and bladder training, 89 (32.48\%) were not satisfied, 207 (75.55\%) patients were satisfied on how the nurses taught them and their families the need to visit the hospital for check-ups after discharge, 67 (24.45\%) were not satisfied.

\section{Hypothesis}

From Table 3, the results of the Chi-square above are greater than $(p>0.05)$, therefore the null 
hypothesis (H0) is accepted showing that there is no significant difference between prostate cancer patients' perception of pre-operative care provided by the nurses at NAUTH Nnewi, UNTH Enugu and FETH Abakaliki. This implies that the type of health institution has no influence on the type of tasks performed by the nurses.

\section{Discussions}

The major findings of the study were discussed based on the two research questions and the tested hypothesis. The findings revealed that prostate cancer patients' perception of pre-operative care provided by the nurses at the selected tertiary health institutions was satisfactory in six (6) pre-operative care items and not satisfactory in seven (7) pre-operative care items. Nursing procedures that were satisfactorily performed include: Nurses monitored patients vital signs and recorded findings; encouraged patients family members to support them; assisted patients to sign the consent form for the surgery; gave patients their drugs as at and when due; assisted patients to have their personal hygiene of bathing and oral care and cared for patients indwelling urinary catheter that prevented blockage of their urethra catheter.

The result showed that patients perceived the pre-operative care provided by the nurses are satisfactory. This is in line with Charlotte, et al. [7] who found out that pre-operative care provided by the nurses was satisfactory as perceived by the patients and there was also good outcome of the surgery. However nurses provided these care in order to familiarize the patients with pre-operative experience and reduce anxiety about the surgery. This supports the statement of Townsend [8] that the major pre-operative goals for the patients going for surgery were to reduce anxiety and learn about the prostate disorder. In spite of these performances there are still areas of nursing care which were obviously not satisfactorily perceived by the patients. They include: Nurses explaining prostate cancer disease diagnosis to patients and their relations to reduce anxiety; clarifying patient's questions about prostate cancer disease; explaining and supporting patients and relatives with treatment options; providing privacy to patients during the care and measuring their urinary output.

The findings of this study are in line with that of Iman, et al. [5] that 189 (68\%) of the respondents perceived some of the pre-operation nursing care as unsatisfactory as majority (75\%) expressed feelings of anxiety about the surgery. However it is important to note that discomfort like pains may have affected patient's perception of the care. Nurse should always try to improve patient's condition by relieving discomfort. This supported the statement of Kelvin [9] that if patient experience discomfort about surgery, prescribed analgesics agents should be administered and measures are also initiated to relieve anxiety.

The findings of this study also revealed that prostate cancer patients' perception of most post-operative care provided by the nurses at the selected tertiary health institutions was satisfactory. This is in line with the findings of Onyeneke, Uzoka, Obieke and Okafor [10] that 200 (75.2\%) of the patients were satisfied with how their post-operative pains were relieved with post-operative analgesic drugs and they perceived the care as satisfactory. Nurses were able to perform satisfactorily in post operative care because of their knowledge of risk of poor post-operative management that will result in complications and sudden death.

This supports the findings of Leila [11] and Smith and Crawford [12] that after prostatectomy, nurses monitored prostate cancer patients closely for major complication such as hemorrhage, shock, infection, deep vein thrombosis, urinary catheter obstruction which will result in poor outcome of the surgery. However, this finding disagrees with that of Charlotte et al. [7] that men treated with prostatectomy do not receive individualized support and nursing care needed and so did not perceive the care as satisfactory. 


\section{Conclusion and Recommendations}

This study on perception of nursing care provided by the nurses to patients with prostate cancer at selected tertiary health institutions in South-East, Nigeria revealed patients' satisfactory perception of post-operative nursing care while pre-operative care was unsatisfactory. Findings revealed that anxiety about the surgery and non-understanding of some of the nurses' procedures were the contributory factors that affected patients' perception. Therefore since nurses were aware of these discomforts they should try to limit these discomforts and establish trusting relationships with their patients. Also nurses should improve their skills in management of prostate cancer cases especially in pre-operative management. There is also the need to empower nurses with more information on prostate cancer management to enable them to provide suitable quality care.

\section{References}

[1] Carlo, A. O., and Wolfgang, S. K. 2010. "Guideline for the Early Detection of cancer.” Journal of American Cancer Society. Retrieved on 15/5/16 from www.cancerorg/docroot/ped/content/ped cancer detection guidelines.

[2] Alan, T. L., Lefor, M. M., Merino, S. M., and Jack, A. M. 2010. "Five Things Physicians and Patient Should Question.” Journal of Clinical Oncology.” Retrieved on 15/5/16 from http://choosing-wisely.org/wp-content/uploads/5things.

[3] Osegbe, N. 2012. "Increased Incidence of Prostate Cancer in Nigerians.” Nigerian Journal of Medical Association 91
(3): 159-64.

[4] Bowa, K. 2012. "An Overview of the Diagnosis and Management of Prostate Cancer in Nigeria: Experience from Northern Nigeria Africa." PMID 9: 111-2, 20710098.

[5] Iman, O. O, Okunlade, K. C., and Oladeji, O. P. 2011. “To Ascertain Perceptions of Nursing Care Rendered to Prostate Cancer Patients before Surgery and Effects of the Interventions." International Professional Nursing Journal 20 (2): 224-7.

[6] Omar, N., and Onokunde, K. C. 2012. "An Overview of Management of Prostate Cancer Cases, Nurses Interventions and Patients' Perceptions.” Nigerian Journal of Clinical Practice 10 (5): 95-8.

[7] Charlotte, K., Christian, A., and Birgitte, D. 2011. "Men with Prostate Cancer and Their Accessibility to Information in U.K.” Journal of Nursing Education 34 (3): 115-22.

[8] Townsend, K. 2014. "Patients' Satisfaction with a Nurse-Led Clinic for Men with Prostate Cancer in Bridgend.” Retrieved on 15/2/16 from http://dx.doi.org/10.1016/j.profnurs, PMID 19306834.

[9] Kelvin, E. A. 2004. Nursing Management of Prostate Cancer; Current Clinical Oncology Totowa. NJ: Humana Press.

[10] Onyeneke, C. O., Uzoka, K. C., Obieke, O. C., and Okafor, J. C. 2011. "To Determine Post-Operative Practices of Patients Received Treatment and Their Perceptions of the Care at University of Nigeria Teaching Hospital Enugu.” Nigeria Journal of Clinical Practice 10 (3): 112-4.

[11] Leila, C. 2014. "Prostate Cancer: Patients' Perceptions of What Constitutes a Good Nurse in Belgium.” Journal of

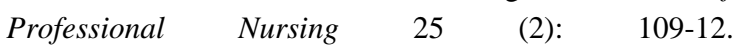
doi:10.5823/j.lib,20140402.03.

[12] Smith, J., and Crawford, L. 2011. “Assessment of Nurse Competence and Effect of Duration of Practice in Clinical Performance.” Journal of Nursing Education 45 (9): 379-834. 